\title{
Effectiveness of the Implemented Training Program in Changing Menopausal Women's Knowledge \& Opinion toward Osteoporosis
}

\author{
*Seham Shehata Ibrahim, ** Sanaa Ali Nour\&* Fatma Zaky Mohamed Farahat \\ *Department of Maternity, Gynecology \& Obstetric Nursing, Faculty of Nursing, Port Said University, Egypt \\ ** Department of Maternal and Newborn Health Nursing, Faculty of Nursing, Zagazig University, Eygept.
}

\begin{abstract}
:
Background: Osteoporosis Is A Major Global Public Health Problem And An Important Metabolic Bone Disease Associated With Significant Morbidity, Mortality, And Socioeconomic Burden. It Is Defined As A Skeletal Disorder Characterized By A Decrease In Bone Mass And Density, Leading To An Increased Risk Of Fragility Fractures. The Greatest Bone Loss Occurs In Women During Per-Menopause And Is Associated With Estrogen Insufficiency, A Condition Of Menopause.

Aim: To Evaluate The Effectiveness Of Implemented Training Program In Changing Menopausal Women's Knowledge And Opinion Toward Osteoporosis At Rheumatic And Rehabilitation Outpatients' Clinic In Mansoura University Hospital. Design: A Quasi-Experimental Design Was Used. Sample: Two Types Of Sample Were Recruited For This Study. The First Total 400 Menopausal Women Attending The Previous Mentioned Clinic Between May2012and March 2013. The Second Sample 120 Menopausal Women With Positive Diagnosis Of Osteoporosis. Tools For Data Collection: Three Tools Were Devised Specifically For The Study.Results: There Were Significant Improvements In The Women's Knowledge Scores About Osteoporosis Especially Related To Definition, Causes, Signs And Symptoms, Risk Factors, Intervention, Diagnosis And Nursing Management. Meanwhile, The Scores In The Follow Up (After 3 Months) Tended To Decline. Conclusion: The Women's Knowledge About Osteoporosis Was Significantly Improved During The Program Phases; At The Post Test And Follow Up After 3 Months. The Study Recommended That The Approach Can Be Replicated And Applied To Other Groups Of Menopausal Women.
\end{abstract}

Keywords: Training Program, Osteoporosis, Menopausal Women's Knowledge, Opinion.

\section{Introduction}

Osteoporosis is a worldwide problem because of the fractures that occur. The burden of fractures is increasing in direct correlation with life expectancy. This increase is greater in underdeveloped countries. By 2030, the increase in the aged population will affect developing countries more than developed ones and this increase will occur in both sexes. According to the National Osteoporosis Foundation (NOF), the number of postmenopausal women in the United States will double over the next 20 years, leading to a tripling of the number of osteoporotic fractures in 2040. The International Osteoporosis Foundation (IOF) estimates that 200 million women suffer from osteoporosis across the world. Moreover, osteoporosis has been misconceived as a women's disease because it also affects men significantly. Indeed, at least one in five men compared to one in three women over the age of 50 will have an osteoporosis-related fracture in their remaining lifetime ${ }^{(1)}$.

Johnell and Kanis (2008) ${ }^{(2)}$ reported that, 8 million women in the United States had osteoporosis, $13 \%$ of them aged 50 years, $27 \%$ were older than 60 years, $47 \%$ were older than 70 years and $67 \%$ were aged 80 years. Also, it was estimated that $20 \%$ of patients who had an osteoporosis fracture die within one year but In China the prevalence of osteoporosis among the elderly women aged 60 years and over was 30\%.In a similar study, Dennison and Cooper (2006) ${ }^{(3)}$ in the United Kingdom found that, osteoporosis risk was high and ranges between $40-50 \%$ in aged women and hip fractures rate will be increased from 46,000 in 1985 to 117,000 in 2016. However, Riggs and Melton, (2007) ${ }^{(4)}$ revealed that, in Canada the prevalence of osteoporosis was $16 \%$ in women aged 50 years or older, almost 300.000 hip fractures occur each year and 70$90 \%$ of hip fractures are caused by osteoporosis.

The mean age of the menopause in Egypt is 46.7 years, which is low compared to many countries, but this age has been rising in the past few years in the west, probably because of the different socio-cultural attitudes towards the menopause in different communities. The western woman attitude towards the menopause is generally positive and about one third of them considers the menopause as a normal physiological change ${ }^{(5)}$. 
Osteoporosis is a clinically silent disease until it manifests in the form of fractures. The most common osteoporotic fracture sites are the vertebrae, followed by the hip and distal forearm. Patients may present with complaints of loss of height, bony pain or kyphotic posture without pain ${ }^{(6)}$

Several risk factors for osteoporosis and fractures have been identified from an extensive research base. Large prospective population-based studies, such as the study of osteoporotic fractures (SOF) for women in the United States, provide well-developed multivariable models of risk factors for osteoporosis and fractures .Loss of height may be a sign of vertebral fracture in postmenopausal women. After achieving maximal height, women can lose up to 1 to 1.5 inches of height as part of the normal aging process, primarily as a result of shrinkage of intervertebral disks. In otherwise asymptomatic women, height loss greater than 1.5 inches increases the likelihood that a vertebral fracture is present. Height should be measured annually with an accurate method, such as a wall-mounted ruler or a stadiometer ${ }^{(7)}$

Effective disease management programs for osteoporosis involve patient education, recurrent body mass index (BMD) assessment, and the use of non-pharmacologic and pharmacologic interventions. The nursing role focuses on client education about prevention of disease, the identification and minimization of controllable risk factors ${ }^{(8)}$. Since maternity nurse is the professional person that can help the menopausal women to achieve high level functioning at her life through helping women to understand the physical and psychological changes during menopause to decrease unpleasant symptoms, also, increase women awareness about osteoporosis ${ }^{(9)}$. Hence, this study was undertaken to find out the risk factors encountered among menopausal women in turn to increase awareness, education, prevention, and treatment of osteoporosis, and to evaluate the result of intervention done for treatment/progress of the disease. The aim of this study was to evaluate the effectiveness of implemented training program in changing menopausal women knowledge and opinion toward osteoporosis.

\section{Hypothesis}

$\mathrm{H}_{1}$ : The knowledge of osteoporotic women about osteoporosis post program will be higher than pre program.

\section{Subjects and methods}

A quasi-experimental design was used to conduct this study. The research was carried out in two phases and two types of sample were selected for this study. Concerning the first sample: All menopausal women (400) attending the Rheumatic and Outpatient Clinic for follow-up, during the period of the study. This study was carried out in the Rheumatic and Rehabilitation Outpatients' Clinic in Mansoura University Hospital, Egypt. This hospital is a teaching hospital affiliated to the Ministry of High Education. It attracts women from all over Dakahlia Governorate, but principally from Mansoura City and all nearby areas. It provides low cost heath services for women with obstetric and gynecological problems compared with other private centers and clinics.

One tool includes three parts and an educational program were developed and used by the researchers for data collection:

\section{Tools for data collection:}

A structured interviewing questionnaire form was designed by the researchers based on relevant literature and years of experience, in the field of the study to assess the effectiveness of the training program. It will consist of the following three parts:

1) socio-demographic data: such as: age, occupation and education.2) Knowledge and opinion questionnaire sheet to assess: women's knowledge regarding osteoporosis as: definition, risk factors and consequences and investigations. 3) Women's opinion concerning the prevention measures and management of osteoporosis.

\section{Scoring system:}

For the knowledge items, a correct response was scored 1 and the incorrect zero. For each area of knowledge, the scores of the items were summed-up and the total divided by the number of the items, giving a mean score for the part. These scores were converted into a percent score, means and standard deviations were computed. Knowledge was considered satisfactory if the percent score was $60 \%$ or more and unsatisfactory if less than $60 \%$. Each statement had 3 levels of answers, For opinion: "always", "sometimes", and "never". These were respectively scored 3, 2, and 1 . Scoring was reversed for negative statements. The scores of the items were summed-up and the total divided by the number of the items, giving a mean score. These scores were converted into a percent score, and means and standard deviations were computed. The opinion was considered positive if the percent score was $60 \%$ or more, and negative if less than $60 \%$.

\section{Educational Program:}

The program was conducted through three phases, planning, implementation, and evaluation Phase I (Program Planning): The program was designed based on the identified needs and demands of women, and in the light of the most recent pertinent literature. Phase II (Program Implementation): The training program was implemented for recruited women. Each session took about two hours per day. The program was presented 
in clear and concise form, using different teaching methods such as discussion, simulations, and role-playing. A booklet prepared by the researcher was distributed to the participants. Since it was difficult to fit all the study subjects at the same time in the program, the training program was implemented for a group of 10-15 women in 3 sessions. Each session took about one hour and at the end of each session each women was assessed for her understanding of the instructions. Different teaching methods as short lecture, group discussion, role playing, demonstration, and re-demonstration, were used. Also different audio visual materials were used as pamphlets, small books, diagrams picture, posters, real equipments and life situations. These were used to facilitate teaching of each topic. Phase III (Evaluation Phase): After program implementation, a post-test was done immediately. Then, a follow-up test was done after four months of program implementation. The same study tools were used to evaluate the effect of the training program on the women's knowledge, opinion, by comparing the results before program with those after and follow-up phases.

\section{Tools validity and reliability}

The tools were developed by the researchers based on review of related literature and similar studies tools. They were exposed to face and content-validation by a panel of experts in the obstetrics and gynecology field from nursing and medical discipline. The reliability of the tools was assessed through measuring their internal consistency using Cronlach alpha coefficient method.

\section{Pilot Study:}

Before embarking on the actual study, a pilot study was conducted on 40 (10\% of the study sample) menopausal women, who were excluded from the main study sample. It was done for evaluating the applicability and clarity of the tools as well as assessing the feasibility of the study and finding the possible obstacles and problems that might face the researchers and interfere with data collection. It also aimed to estimate the time needed for the interview and filling in the tools. Modifications were done according to the pilot results. The time required for the interview with each subject was 30 minutes.

\section{Results}

Figure (1) illustrates the percentage distribution of osteoporosis detected in the studied women. It indicates that osteoporosis was found in less than three fifths studied women $(58.7 \%)$, while the non-osteoporosis women presented $41.3 \%$ of the women.

Table (1) shows the comparison between women in the study (osteoporotic) and control (non osteoporotic) groups regarding their socio-demographic characteristics. Women over 50 years of age were more likely to have osteoporosis than the control group (67.9\% vs. $65.6 \%$ respectively). Meanwhile, more than two thirds $(67.1 \%)$ of osteoporotic women were illiterate or could read and write compared to $53.4 \%$ of the non osteoporotic group. They also had more housewives and married women compared to the control group ( $75.9 \%$ vs $68.7 \% 7 \& 69.6 \%$ vs $62.0 \%$ respectively).

Table (2) points to (statistically significant differences between the osteoporotic and control non osteoporotic regarding their reproductive history). It is clear that more women in the osteoporotic group (30.4\%) had an early age of menarche (9-11 years), heavy amount of the menstruation (31.2\%) compared to the control group (19.0\% $\& 23.4 \%$ respectively). More women in the osteoporotic group had 4+ gravid and Para compared to the control group $(65.8 \%$ \& $52.3 \%$ vs. $55.3 \%$ \& $46.7 \%$ respectively). Meanwhile, they had history of previous abortion (48.0\%) compared to the control group $(41.7 \%)$. (However, differences observed are not statistically significant).

Table (3) points to statistically significant improvements are noticed at both the post-program ( $<<0.001)$, and follow-up $(p<0.001)$ phases. The percent of women having the ability to Inadequate calcium intake, Decrease protein intake, Inadequate intake of water and Increase use of steroids, as they decrease bone density. From a pre-program level of $(41.7 \%, 48.3 \%, 50.8 \% \& 56.7)$ to a post-program level of $(9.2 \%, 10.8 \%, 14.2 \% \& 15.8 \%)$ and follow-up level of $(33.3 \%, 19.2 \%, 30 \% \& 30 \%)$ at the follow up phase of the program.

Table (4) points to statistically significant improvements in women's knowledge about osteoporosis at the posttest and the follow up $(\mathrm{P}=<0.001)$. As the table shows the percent knowledge scores at the pre-test was slightly more than one tenth and ranges between $10.8 \%-14.2 \%$ for the definition of osteoporosis, causes, signs and symptoms, and medication used respectively. At the post-test and follow up the proportion rose up to reach between two thirds and three fourth who gave complete answers, $(65.8 \%, 68.3 \%, 73.3 \%$ and $64.2 \%$ respectively), and $60.8 \%$ for how to prevent osteoporosis. 
Table (5) indicates the number and percent distribution of the studied subjects according to measures of controlling osteoporosis over time. It is evident that there were statistically significant changes after the program and in the follow up in relation to patient's compliance to the medication, BMI and Dexa screening $(\mathrm{P}=<0.001)$, prevention of osteoporosis $(\mathrm{P}=<0.001)$, as well as avoiding fractures $(\mathrm{P}=<0.001)$.

Table (6) shows the relation between studied women with osteoporosis total score of knowledge and score level of knowledge regarding life style practices and compliance. It is clear from the table that women's knowledge scores was improved after the implementation hence, before the program as none of the women who have "good knowledge level compared to $66.7 \%$ immediate the program. Regarding the women's knowledge of life style practices, scores of the study group, the majority of those who had "good knowledge level also had "unsatisfactory" practice $8.3 \%$ immediately the program.

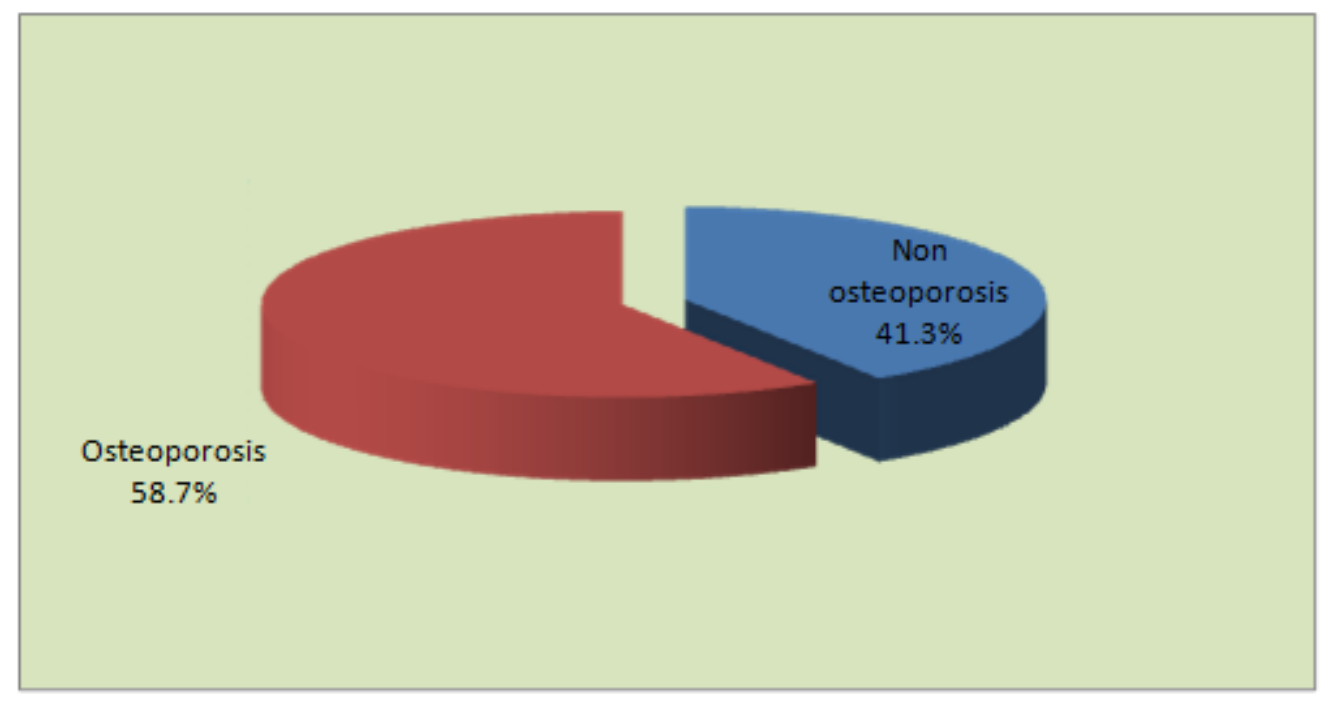

Figure (1) Prevalence of osteoporosis

Table (1): Distribution of the studied women according to their socio-demographic characteristics

\begin{tabular}{|c|c|c|c|c|}
\hline \multirow[t]{2}{*}{ Socio-demographic Characteristics } & \multicolumn{2}{|c|}{$\begin{array}{l}\text { Non-Osteoporotic } \\
(\mathbf{n}=\mathbf{1 6 3})\end{array}$} & \multicolumn{2}{|c|}{$\begin{array}{c}\text { Osteoporotic } \\
(\mathbf{n}=\mathbf{2 3 7})\end{array}$} \\
\hline & No. & $\%$ & No. & $\%$ \\
\hline \begin{tabular}{|l|} 
Age: \\
$40-45$ \\
$46-50$ \\
$51-60$
\end{tabular} & $\begin{array}{c}28 \\
28 \\
107\end{array}$ & $\begin{array}{l}17.2 \\
17.2 \\
65.6\end{array}$ & $\begin{array}{c}30 \\
46 \\
161\end{array}$ & $\begin{array}{l}12.7 \\
19.4 \\
67.9\end{array}$ \\
\hline \begin{tabular}{|l} 
Education: \\
Read \& Write \\
Primary\& preparatory \\
Secondary \\
University-more \\
\end{tabular} & $\begin{array}{l}87 \\
21 \\
34 \\
21 \\
\end{array}$ & $\begin{array}{l}53.4 \\
12.9 \\
20.9 \\
12.8 \\
\end{array}$ & $\begin{array}{c}159 \\
16 \\
44 \\
18\end{array}$ & $\begin{array}{c}67.1 \\
6.8 \\
18.5 \\
7.6 \\
\end{array}$ \\
\hline $\begin{array}{l}\text { Occupation: } \\
\text { House wife } \\
\text { Working }\end{array}$ & $\begin{array}{c}112 \\
51\end{array}$ & $\begin{array}{l}68.7 \\
31.3\end{array}$ & $\begin{array}{c}180 \\
57\end{array}$ & $\begin{array}{l}75.9 \\
24.1\end{array}$ \\
\hline \begin{tabular}{|l|} 
Social status: \\
Married \\
Single \\
Divorced \\
Widow \\
\end{tabular} & $\begin{array}{c}101 \\
1 \\
0 \\
61\end{array}$ & $\begin{array}{c}62.0 \\
0.6 \\
0.0 \\
37.4\end{array}$ & $\begin{array}{c}165 \\
1 \\
8 \\
63\end{array}$ & $\begin{array}{c}69.6 \\
0.4 \\
3.4 \\
26.6\end{array}$ \\
\hline
\end{tabular}


Effectiveness of the Implemented Training Program in Changing Menopausal Women's Knowledge ...

Table (2): Distribution of the studied women according to menstrual history $(n=400)$.

\begin{tabular}{|c|c|c|c|c|}
\hline \multirow[t]{2}{*}{ Reproductive History } & \multicolumn{2}{|c|}{$\begin{array}{r}\text { Non-Osteoporotic } \\
(\mathrm{n}=\mathbf{1 6 3})\end{array}$} & \multicolumn{2}{|c|}{$\begin{array}{l}\text { Osteoporotic } \\
(\mathbf{n}=\mathbf{2 3 7})\end{array}$} \\
\hline & No & $\%$ & No & $\%$ \\
\hline $\begin{array}{l}\text { Age of Menarche: } \\
9-11 \\
12-14 \\
15+ \\
\end{array}$ & $\begin{array}{l}31 \\
98 \\
34\end{array}$ & $\begin{array}{l}19.0 \\
60.1 \\
20.9\end{array}$ & $\begin{array}{c}72 \\
126 \\
39\end{array}$ & $\begin{array}{l}30.4 \\
53.2 \\
16.4\end{array}$ \\
\hline $\begin{array}{l}\text { Duration of Menstruation: } \\
3-5 \\
6-9 \\
9+ \\
\end{array}$ & $\begin{array}{c}94 \\
65 \\
4 \\
\end{array}$ & $\begin{array}{c}57.6 \\
39.9 \\
2.5 \\
\end{array}$ & $\begin{array}{c}134 \\
93 \\
10 \\
\end{array}$ & $\begin{array}{c}56.5 \\
39.3 \\
4.2 \\
\end{array}$ \\
\hline \begin{tabular}{|l|} 
Amount of blood flow \\
Mild or light \\
Moderate \\
Heavy \\
\end{tabular} & $\begin{array}{c}3 \\
122 \\
38\end{array}$ & $\begin{array}{c}1.8 \\
74.8 \\
23.4\end{array}$ & $\begin{array}{c}13 \\
150 \\
74\end{array}$ & $\begin{array}{c}5.5 \\
63.3 \\
31.2\end{array}$ \\
\hline $\begin{array}{l}\text { Number of gravid: } \\
\text { Non } \\
1-3 \\
4+ \\
\end{array}$ & $\begin{array}{c}3 \\
70 \\
90\end{array}$ & $\begin{array}{c}1.8 \\
42.9 \\
55.3\end{array}$ & $\begin{array}{c}1 \\
80 \\
129\end{array}$ & $\begin{array}{c}0.4 \\
33.8 \\
65.8\end{array}$ \\
\hline $\begin{array}{l}\text { Number of abortion: } \\
\text { None } \\
1-3 \\
4+ \\
\end{array}$ & $\begin{array}{c}95 \\
66 \\
2\end{array}$ & $\begin{array}{c}58.3 \\
40.5 \\
1.2\end{array}$ & $\begin{array}{c}123 \\
102 \\
12\end{array}$ & $\begin{array}{c}51.9 \\
43.0 \\
5.0\end{array}$ \\
\hline $\begin{array}{l}\text { Parity: } \\
\text { None } \\
1-3 \\
4+ \\
\end{array}$ & $\begin{array}{c}7 \\
80 \\
76\end{array}$ & $\begin{array}{c}4.2 \\
49.1 \\
46.7\end{array}$ & $\begin{array}{c}7 \\
106 \\
124\end{array}$ & $\begin{array}{c}3.0 \\
44.7 \\
52.3\end{array}$ \\
\hline
\end{tabular}

Table (3): Distribution the studied subjects regarding their nutritional life style practice for reducing osteoporosis nutritional risk factors at the different phases of intervention $(n=120)$.

\begin{tabular}{|c|c|c|c|c|c|c|c|c|c|c|c|c|c|}
\hline \multirow[t]{2}{*}{ Item } & \multirow[t]{2}{*}{ Time of Assessment } & \multicolumn{2}{|c|}{ Usually } & \multicolumn{2}{|c|}{ Sometimes } & \multicolumn{2}{|c|}{ Never } & \multirow{2}{*}{$x^{2}(1)$} & \multirow{2}{*}{$\mathrm{P}$} & \multirow{2}{*}{$x^{2}(2)$} & \multirow{2}{*}{$\mathrm{P}$} & \multirow{2}{*}{$x^{2}(3)$} & \multirow{2}{*}{$\mathrm{P}$} \\
\hline & & No & $\%$ & $\mathrm{~N}_{0}$ & $\%$ & $\mathrm{~N}_{0}$ & $\%$ & & & & & & \\
\hline \multirow{3}{*}{ Inadequate calcium intake } & Pre & 50 & 41.7 & 57 & 47.5 & 13 & 10.8 & \multirow{3}{*}{74.42} & \multirow{3}{*}{$<0.001^{88}$} & \multirow{3}{*}{41.35} & \multirow{3}{*}{$<0.001^{88}$} & \multirow{3}{*}{20.97} & \multirow{3}{*}{$<0.001^{88}$} \\
\hline & Immediate-post & II & 9.2 & 34 & 28.5 & $7 / 2$ & 62.2 & & & & & & \\
\hline & Follow-up & 40 & 33.3 & 24 & 20.0 & 56 & 46.7 & & & & & & \\
\hline \multirow{3}{*}{ Inadequate ritamin $D$ intake. } & Pre & 64 & 53.3 & 43 & 35.8 & 13 & 10.8 & \multirow{3}{*}{83.90} & \multirow{3}{*}{$<0.001^{88}$} & \multirow{3}{*}{23.69} & \multirow{3}{*}{$<0.001^{88}$} & \multirow{3}{*}{38.46} & \multirow{3}{*}{$<0.001^{88}$} \\
\hline & Immediate-post & 10 & 8.5 & 32 & 29.2 & 72 & 62.2 & & & & & & \\
\hline & Follow-up & 28 & 23.3 & 64 & 53.3 & 28 & 23.3 & & & & & & \\
\hline & Pre & 62 & 51.7 & 43 & 35.8 & 15 & 12.5 & & & & & & \\
\hline Eating hot and spicy foods & Immediate-post & 9 & 7.5 & $3 !$ & 25.8 & 80 & 66.7 & 85.98 & $<0.001^{88}$ & 34.35 & $<0.001^{88}$ & 18.47 & $=0.001^{88}$ \\
\hline & Follow-up & 24 & 20.0 & 48 & 40.0 & 48 & 40.0 & & & & & & \\
\hline & Pre & 63 & 52.5 & 43 & 35.8 & 14 & 11.7 & & & & & & \\
\hline Increase intake of colas sodas & Immediate-post & 10 & 8.3 & $4 !$ & 34.2 & 69 & 57.5 & 74.97 & $<0.001^{88}$ & 25.39 & $<0.001^{88}$ & 22.87 & $<0.001^{88}$ \\
\hline & Follow-up & 40 & 33.5 & 32 & 26.7 & 48 & 40.0 & & & & & & \\
\hline & Pre & 34 & 28.3 & 73 & 60.8 & 13 & 10.8 & & & & & & \\
\hline Decrease fiber intake & Immediate-post & 6 & 5.0 & 44 & 36.7 & 70 & 58.3 & 65.93 & $=0.001^{88}$ & 16.84 & $<0.001^{88}$ & 20.70 & $=0.001^{88}$ \\
\hline & Follow-up & 40 & 33.3 & 32 & 26.7 & 48 & 40.0 & & & & & & \\
\hline & Pre & 58 & 48.5 & 48 & 40.0 & 14 & II.T & & & & & & \\
\hline Decrease protein intake & Immediate-post & 13 & 10.8 & 45 & 37.5 & 62 & 21.6 & 59.07 & $<0.001^{88}$ & 17.52 & $<0.001^{88}$ & 15.93 & $=0.001^{88}$ \\
\hline & Follow-up & 23 & 19.2 & 58 & 48.3 & 39 & 32.2 & & & & & & \\
\hline & Pre & $6 !$ & 50.8 & 47 & 39.2 & 12 & 10.0 & & & & & & \\
\hline Inadequate intake of water. & Immediate-post & IT & 14.2 & 47 & 39.2 & 56 & 46.7 & 53.29 & $<0.001^{88}$ & 12.02 & $<0.001^{88}$ & 21.19 & $=0.001^{88}$ \\
\hline & Follow-up & 36 & 30.0 & 60 & 50.0 & 24 & 20.0 & & & & & & \\
\hline & Pre & 45 & 37.5 & 60 & 50.0 & 15 & 12.5 & & & & & & \\
\hline Increase foods high in fat. & Immediate-post & .14 & II. & 48 & 40.0 & 28 & 48.3 & 42.95 & $<0.001^{18}$ & 39.48 & $<0.001^{88}$ & 7.90 & $<0.05^{8}$ \\
\hline & Follow-up & 28 & 23.3 & 32 & 26.7 & 60 & 50.0 & & & & & & \\
\hline & Pre & 45 & 37.5 & 57 & 47.5 & 18 & 15.0 & & & & & & \\
\hline Increase sugar and salt in intake. & Immediate-post & 24 & 20.0 & 38 & 31.7 & 58 & 48.3 & 31.24 & $<0.001^{88}$ & 39.65 & $<0.001^{88}$ & 2.11 & $<0.001^{88}$ \\
\hline & Follow-up & 28 & 23.5 & 28 & 25.5 & 64 & 23.3 & & & & & & \\
\hline & Pre & 68 & 56.7 & 38 & 31.7 & 14 & 11.7 & & & & & & $20.05^{8}$ \\
\hline Increase use of steroids, as they & Immediate-post & 19 & 15.8 & 45 & 37.5 & 56 & 46.7 & 53.38 & $<0.001^{88}$ & 25.41 & $<0.001^{88}$ & 6.90 & \\
\hline decrease bone density & Follow-up & 36 & 30.0 & 40 & 33.3 & 44 & 36.7 & & & & & & \\
\hline & Pre & 57 & 47.5 & 60 & 50.0 & 3 & 2.5 & & & & & & $20.05^{8}$ \\
\hline Decrease iron intake. & Immediate-post & 15 & 1.2 .5 & 39 & 32.5 & 66 & 55.0 & 113.40 & $<0.001^{88}$ & 63.15 & $<0.001^{88}$ & 7.65 & \\
\hline & Follow-up & 32 & 26.7 & 32 & 26.7 & 56 & 46.7 & & & & & & \\
\hline
\end{tabular}

(*) Statistically significant at $\mathbf{P}<0.0$ 
Table (4): Knowledge distribution of the studied women regarding osteoporosis at the different phases of intervention $(\mathbf{n}=\mathbf{1 2 0})$.

\begin{tabular}{|c|c|c|c|c|c|c|c|c|c|c|c|c|}
\hline \multirow[t]{2}{*}{ Items of knowledge } & \multicolumn{2}{|l|}{ Pre } & \multicolumn{2}{|c|}{ Post } & \multicolumn{2}{|c|}{ Follow up } & \multirow{2}{*}{$x^{2}(1)$} & \multirow{2}{*}{$P$} & \multirow[b]{2}{*}{$x^{2}(2)$} & \multirow[b]{2}{*}{ p } & \multirow[b]{2}{*}{$x^{2}(3)$} & \multirow[b]{2}{*}{ p } \\
\hline & $\mathrm{N}_{0}$ & $\%$ & $\mathrm{~N}_{0}$ & $\%$ & No & $\%$ & & & & & & \\
\hline \multicolumn{13}{|c|}{ Define the osteoporosis } \\
\hline Incomplete answer & 107 & 89.2 & 41 & 34.2 & 48 & 40 & \multirow{2}{*}{74.47} & \multirow{2}{*}{$<0.001$} & \multirow{2}{*}{63.23} & \multirow{2}{*}{$<0.001$} & \multirow{2}{*}{1.18} & \multirow[b]{2}{*}{$>0.05^{*}$} \\
\hline Complete answer & 13 & 10.8 & 79 & 65.8 & 72 & 60.0 & & & & & & \\
\hline \multicolumn{13}{|c|}{ Causes of osteoporosis } \\
\hline Incomplete answer & 106 & 88.4 & 38 & 31.6 & 44 & 36.6 & \multirow{2}{*}{68.33} & \multirow{2}{*}{$<0.001$} & \multirow{2}{*}{79.59} & \multirow{2}{*}{$<0.001$} & \multirow{2}{*}{0.808} & \multirow{2}{*}{$>0.05 *$} \\
\hline Complete answer & 14 & 11.7 & 82 & 68.3 & 76 & 63.3 & & & & & & \\
\hline \multicolumn{13}{|c|}{ Signs and symptoms of osteoporosis } \\
\hline Incomplete answer & 103 & 85.9 & 32 & 26.6 & 40 & 33.3 & \multirow{2}{*}{77.93} & \multirow{2}{*}{$<0.001$} & \multirow{2}{*}{72.31} & \multirow{2}{*}{$<0.001$} & \multirow{2}{*}{1.57} & \multirow{2}{*}{$>0.05 *$} \\
\hline Complete answer & 17 & 14.2 & 88 & 73.3 & 80 & 66.7 & & & & & & \\
\hline \multicolumn{13}{|c|}{ Medication affecting osteoporosis } \\
\hline Incomplete answer & 105 & 87.5 & 43 & 35.9 & 48 & 40 & \multirow{2}{*}{65.56} & & & & & \\
\hline Complete answer & 15 & 12.5 & 77 & 64.2 & 72 & 60.0 & & $<0.001$ & 76.27 & 80.001 & 01.32 & $>0.05^{*}$ \\
\hline Prevention of osteop & & & & & & & & & & & & \\
\hline$>0.05^{*}$ & 105 & 87.5 & 43 & 35.9 & 48 & 40 & 6556 & $<0$ & 6700 & $<0001$ & 241 & \\
\hline Complete answer & 15 & 12.5 & 77 & 64.2 & 74 & 61.7 & 05.20 & $\$ 0.001$ & 07.99 & 80.001 & 2.41 & \\
\hline How to prevent the & oporo & & & & & & & & & & & \\
\hline Incomplete answer & 103 & 85.9 & 47 & 39.2 & 54 & 45 & 5377 & $<0$ & 6403 & & 0.070 & \\
\hline Complete answer & 17 & 14.2 & 73 & 60.8 & 66 & 55.0 & 32.77 & $\$ 0.001$ & 04.92 & 0.001 & 0.929 & 0.05 \\
\hline
\end{tabular}

(*) Statistically significant at $P<0.05$ $\chi^{2}(2)=$ relation between pretest $\&$ follow - up $\chi 2(1)=$ relation between pretest\& posttest

$\chi 2(3)=$ relation between posttest \& follow - up

Table (5): Distribution of studied women regarding preventive measures of controlling osteoporosis over time knowledge at the different phases of intervention $(n=120)$.

\begin{tabular}{|c|c|c|c|c|c|c|c|c|c|c|c|c|}
\hline \multirow[t]{2}{*}{ Item } & \multicolumn{2}{|c|}{ Pre } & \multicolumn{2}{|c|}{ Post } & \multicolumn{2}{|c|}{ Follow up } & \multirow{2}{*}{$\not 2(1)$} & \multirow{2}{*}{$\mathbf{P}$} & \multirow{2}{*}{$z^{2}(2)$} & \multirow{2}{*}{$\mathrm{P}$} & \multirow{2}{*}{$\chi^{2}(3)$} & \multirow{2}{*}{$P$} \\
\hline & No & $\%$ & No & $\%$ & No & $\%$ & & & & & & \\
\hline \multicolumn{13}{|c|}{ The importance of preventing fragile fractures } \\
\hline Incomplete answer & 103 & 85.8 & 56 & 46.6 & 63 & 52.5 & \multirow{2}{*}{64.08} & \multirow{2}{*}{$<0.001$} & \multirow{2}{*}{59.52} & \multirow{2}{*}{$<0.001$} & \multirow{2}{*}{0.900} & \multirow{2}{*}{$>0.05^{*}$} \\
\hline Complete answer & 17 & 14.2 & 64 & 53.3 & 57 & 47.5 & & & & & & \\
\hline \multicolumn{13}{|c|}{ The importance of screening } \\
\hline Incomplete answer & 103 & 85.9 & 47 & 39.2 & 54 & 45 & \multirow{2}{*}{71.58} & \multirow{2}{*}{$=0.001$} & \multirow{2}{*}{64.93} & \multirow{2}{*}{$=0.001$} & \multirow{2}{*}{0.929} & \multirow{2}{*}{$>0.05^{*}$} \\
\hline Complete answer & 17 & 14.2 & 73 & 60.8 & 66 & 55.0 & & & & & & \\
\hline \multicolumn{13}{|c|}{ The importance of sports to prevent osteoporosis } \\
\hline Incomplete answer & 98 & 81.6 & 57 & 47.5 & 61 & 50.8 & \multirow{2}{*}{42.48} & \multirow{2}{*}{$<0.001$} & \multirow{2}{*}{39.21} & \multirow{2}{*}{$=0.001$} & \multirow{2}{*}{0.291} & \multirow{2}{*}{$>0.05^{*}$} \\
\hline Complete answer & 22 & 18.3 & 63 & 52.5 & 59 & 49.2 & & & & & & \\
\hline \multicolumn{13}{|c|}{ Treatment of osteoporosis } \\
\hline Incomplete answer & 102 & 85 & 51 & 42.5 & 56 & 46.7 & \multirow{2}{*}{48.98} & & & & & \\
\hline Complete answer & 18 & 15.0 & 69 & 57.5 & 64 & 53.3 & & $=0.001$ & 42.56 & $=0.001$ & 0.213 & $>0.05^{8}$ \\
\hline How to treat osteopol & & & & & & & & & & & & \\
\hline Incomplete answer & 103 & 85.8 & 56 & 46.6 & 63 & 52.5 & & & & & & \\
\hline Complete answer & 17 & 14.2 & 64 & 53.3 & 57 & 47.5 & 64.08 & $=0.001$ & 59.22 & $=0.001$ & 0.900 & $>0.02$ \\
\hline Important of dental $c$ & hing & revent & eth p & blems & & & & & & & & \\
\hline Incomplete answer & 109 & 90.8 & 48 & 40 & 56 & 46.7 & & & & & & \\
\hline Complete answer & 11 & 9.2 & 72 & 60.0 & 64 & 53.3 & 71.9 & $=0.001$ & 61.80 & $=0.001$ & 1.53 & $>0.05^{8}$ \\
\hline
\end{tabular}

(*) Statistically significant at $P<0.05$ $\chi 2(2)=$ relation between pretest $\&$ follow - up $\chi 2(1)=$ relation between pretest $\&$ posttest $\chi 2(3)=$ relation between posttest $\&$ follow - up 
Table (6): Relation between total Scores of knowledge and score level of knowledge regarding life style practices $(\mathbf{n}=\mathbf{1 2 0})$

\begin{tabular}{|c|c|c|c|c|c|c|c|c|c|c|c|c|c|}
\hline & \multirow{3}{*}{ Score } & \multicolumn{6}{|c|}{ Time of Assessment } & \multirow{3}{*}{$z^{2(1)}$} & \multirow{3}{*}{$P$} & \multirow{3}{*}{$z^{2(2)}$} & \multirow{3}{*}{$P$} & \multirow{3}{*}{$z^{2(3)}$} & \multirow{3}{*}{$P$} \\
\hline & & \multicolumn{2}{|c|}{\begin{tabular}{|c|} 
Pre- \\
Interventi \\
on
\end{tabular}} & \multicolumn{2}{|c|}{$\begin{array}{c}\text { Immediate } \\
\text { Post }\end{array}$} & \multicolumn{2}{|c|}{$\begin{array}{l}\text { Follow } \\
\text { up }\end{array}$} & & & & & & \\
\hline & & No & $\%$ & $N_{0}$ & $\%$ & No & \begin{tabular}{|l|}
$\%$ \\
\end{tabular} & & & & & & \\
\hline \multirow{3}{*}{$\begin{array}{c}\text { Total } \\
\text { knowledge } \\
\text { score }\end{array}$} & Poor & 90 & 75.0 & 1 & 0.8 & 5 & 4.2 & \multirow{3}{*}{168} & \multirow{3}{*}{$=0.001^{*}$} & \multirow{3}{*}{147.20} & \multirow{3}{*}{$=0.001^{* *}$} & \multirow{3}{*}{4.74} & \multirow{3}{*}{$=0.05^{*}$} \\
\hline & Average & 30 & 25.0 & 39 & 32.5 & 48 & 40.0 & & & & & & \\
\hline & Good & 0 & 0.0 & 80 & 66.7 & 67 & 55.8 & & & & & & \\
\hline \multirow{2}{*}{$\begin{array}{c}\text { Total } \\
\text { knowledge of } \\
\text { life style } \\
\text { practices score }\end{array}$} & Unsatisfactory & 102 & 85.0 & 10 & 8.3 & 40 & 33.4 & \multirow[b]{2}{*}{138.63} & \multirow[b]{2}{*}{$=0.001^{* *}$} & \multirow[b]{2}{*}{64.17} & \multirow[b]{2}{*}{$=0.001^{88}$} & \multirow[b]{2}{*}{21.24} & \multirow[b]{2}{*}{$=0.001^{*}$} \\
\hline & Satisfactory & 18 & 15.0 & 110 & 91.7 & 80 & 66.7 & & & & & & \\
\hline
\end{tabular}

(*) Statistically significant at $\mathbf{P}<0.05$ $\chi 2(2)=$ relation between pretest $\&$ follow - up $\chi 2(1)=$ relation between pretest $\&$ posttest $\chi^{2}(3)=$ relation between posttest $\&$ follow -up

\section{Discussion}

Osteoporosis is highly prevalent among postmenopausal women, although it can affect people of all ages and both sexes. Worldwide, approximately one-third of women aged 60-70 years and two-thirds of women aged 80 years and older had osteoporosis. The risk of fracture for a 50-year-old white woman is estimated at over $70 \%$, the risk of hip fracture alone is about $14 \%$. Morbidity from fractures is substantial, and mortality is increased by about $20 \%$ after hip fracture (1).

Meanwhile, the present study has revealed statistically significant relations between the occurrence of osteoporosis and certain menstrual characteristics (regularity and heavy menstruation). In this regard, Ebersole and Hess (2004) ${ }^{(\mathbf{1 0})}$ have asserted that a premature menopause, particularly when surgically induced before age 45 years, is a strong determinant of low bone density and increased risk of fracture. Additionally, Nadim et al. (2001) ${ }^{(4)}$ in their study of Screening for osteoporosis: "Risk factors drew from a women health service provision facility in Cairo", have mentioned that early menopause was the most commonly encountered risk factor for osteoporosis.

The implementation of the current study intervention led to significant improvement of the knowledge of women in the post-test and follow up compared with the pre-test. The findings are certainly related to the content of the educational program which was custom-tailored to the needs of the osteoporotic women, and also its process which followed the principles of adult learning with more active participation and open discussion.

In agreement with these present study findings, William and Shiel (2008) ${ }^{(11)}$ evaluated the impact of osteoporotic educational program on gain in knowledge by menopausal women. It was noted that the knowledge of women pertaining to risk factors and consequences of osteoporosis improved considerably after education. On the same line, Abdrrahman et al. (2010) ${ }^{(12)}$ reported that the majority of their patients have insufficient knowledge about causes and predisposing factors of osteoporosis before education which significantly improved after the program.

Considering the Egyptian women's inaccurate or insufficient knowledge and their untoward attitude to the preventive acts of osteoporosis, could be explained by the fact that health professionals, doctors, nurses or mass media as TV or newspapers in the clinic do not usually explain the meaning of the osteoporosis and concentrate on the medical treatment of osteoporosis or bone problems ${ }^{(1)}$. Similar findings concerning women ' knowledge about osteoporosis were revealed by Akkuset al.(2009) ${ }^{(\mathbf{1 3})}$, who found that education increases knowledge about osteoporosis and in turn changes practices of women who have the risk to this disease to the best.

It was obvious from the results of the current study that the majority of the women didn't know the signs and symptoms of osteoporosis and only few women who gave correct answer before the program implementation. This result could be attributed to low awareness about the osteoporosis .This result was supported by Burlet and Reginster (2006) ${ }^{(14)}$. Who reported that slightly more than half of the women of their sample didn't know the main symptoms of osteoporosis

Patient's compliance to adequate dietary practices and therapeutic treatment for osteoporosis are mandatory. The results of the current study revealed that most of the women had incomplete information about 
those aspects before the program. This result was supported by Dennison and Cooper (2006), and Clifford and Roseny (2007) ${ }^{(3,15)}$, which indicates that the women's beliefs are completely in contrary to the desired situation that means perceived benefits are stronger than perceived barriers. Therefore, it seems that the resultant of these two beliefs might weaken the preventive practice.

The implementation of the present study intervention led to significant improvements among the studied women in the post test and follow up in changing their life style and coping with daily life stressors than in the pre test. In this respect, William and Shiel (2008) and Jette et al. (2011) ${ }^{(11,16)}$, have emphasized that health provider should use simple applications and stimulations in order to simplify the information and help attendants to apply their knowledge to practice.

\section{Conclusion}

\section{Based on the results of the present study, it can be concluded that:}

The women's knowledge about osteoporosis was significantly improved during the program phases; at the post test and follow up after 3 months. As well, there were improvements in women's knowledge about the prevention and management of the disease after the implementation of the program.

\section{Recommendations}

Based on the study findings, the following recommendations are required to be implemented:

Changing women lifestyle; in relation to nutrition, exercise, avoiding fractures, receiving appropriate medical treatment, indulging themselves in social activities and coping with life stresses are strategies used to prevent osteoporosis and alleviate its severity.

Increasing women's awareness about osteoporosis and its effect on women's quality of life and upgrading their knowledge about the possible ways of its prevention and treatment.

Further research is required to investigate the effect of counseling program for osteoporotic women on their quality of life

\section{References}

[1]. Kanis JA. Johansson H. Johnell O. Oden A. Eisman JA. Pols H. and Tenenhouse A. (2005): Alcohol intake as a risk factor for fracture. Osteoporosis International. July; 16(7): 737-42.

[2]. Johnell, O., \& Kanis, J. (2008): Epidemiology of osteoporotic fractures. Osteoporosis International, March; $16(2)$ : 3-7.

[3]. Dennison, E., \& Cooper, C. (2006): Epidemiology of osteoporosis. The National Institutes of Health; 32(4): $617-29$.

[4]. Nadim A. Abdel Fattah I. and Rashed A. (2001): Screening for osteoporosis. Risk factors drawn from a women health service provision facility. Second Egyptian International Conference on osteoporosis prevention. Cairo, Egypt.

[5]. Sallam, H., Galal,AF. \&Rashed ,A. (2006): Menopause in Egypt: Past and present perspectives. The Suzanne Mubarak Regional Center for Women's Health and Development, Egypt; 9 (6): 421-429.

[6]. Lin ,JT., \& Lane, JM. (2004): Osteoporosis. Clinical Orthopedics and Related Research. August; 126-34..

[7]. Siminoski, K., Jiang, G., Adachi ,JD., Hanley,DA., Cline ,G., Ioannidis ,G., Hodsman, A., Josse, RG., Kendler, D., Olszynski, WP., St Marie ,LG. \& Eastell, R. (2005): Accuracy of height loss during prospective monitoring for detection of incident vertebral fractures. Osteoporosis International, April; 16(4): 403-10.

[8]. Mahakala, A., Thoutreddy, S, \&Kleerekoper, M. (2003): Prevention and treatment of postmenopausal osteoporosis. Treatments in Endocrinology; 2(5): 331-45.

[9]. Collinge, C., Lebus ,G. \&Gardner ,MJ. (2008): Osteoporosis in orthopedic trauma patients. Diagnosis and Treatment Protocol. The National Institutes of Health; 22(8): 541-7.

[10]. Ebersole P. and Hess P. (2004): Toward Healthy Aging. Human Needs and Nursing Response. $6^{\text {th }}$ ed. Mosby Company; $388-93$.

[11]. William,C.\&Shiel,JR.(2008):Osteoporosis.Available at: http://www.medicinenet.com/osteoporosis/article.htm Last retrieved on: 5/ 3/2012, 10.30 P.M.

[12]. Abdrrahman,W., Delate, CE. \&Van D. (2010): Osteoporosis influencing post menopausal women at E Massoura City. Master thesis, Maternal and Newborn Health Nursing, Faculty of Nursing, Zagazig University.

[13]. Akkus, Z. ,Camdeviren, H. ,\&Celik ,F. ,(2009): Determination of osteoporosis risk factors using a multiple regression model in postmenopausal Turkish women. Saudi Med J; 26(9): 1351-1359.

[14]. Burlet,N., \& Reginster, JY. ,(2006): The first dual acting treatment for postmenopausal osteoporosis. Clinical Orthopedics and Related Research, February; 443: 55-60.

[15]. Clifford, J., \& Rosen, M. (2007): Postmenopausal osteoporosis: Clinical practice. New England Journal of Medicine. Available at: http: www//content.nejm.org/cgi/reprint/353/6/595.pdf Last Accursed on: 1/ 6/2012.9 AM.

[16]. Jette N., Lix LM. Metge CJ. Prior HJ. And McChesney WD. Leslie (2011). Association of Antiepileptic Drugs with Nontraumatic Fractures: A Population-Based Analysis. Archives of Neurology; 68 (1): 107 DOI. 